\title{
Asynchronous Forum as a Discussion Tool in a Preparatory Reading Course for First Year Distance Learners
}

\author{
Maslawati Mohamad ${ }^{1}$, Azura Omar $^{2} \&$ Ahmad Zamri Mansor ${ }^{3}$ \\ ${ }^{1}$ Centre of General Studies, Universiti Kebangsaan Malaysia, Bangi, Selangor, Malaysia \\ ${ }^{2}$ Technical Foundation Section, Universiti Kuala Lumpur-Malaysia France Institute, Malaysia \\ ${ }^{3}$ Centre of General Studies, Universiti Kebangsaan Malaysia, Bangi, Selangor, Malaysia \\ Correspondence: Maslawati Mohamad, Centre of General Studies, National University of Malaysia, 43600 \\ Bangi, Selangor, Malaysia. E-mail: maslawatimohamad@yahoo.com
}

Received: March 4, 2013 Accepted: June 28, 2013 Online Published: September 29, 2013

doi:10.5539/ass.v9n13p53 URL: http://dx.doi.org/10.5539/ass.v9n13p53

\begin{abstract}
This study involved distance learners who enrolled as part time students with the Allied Sciences Faculty, National University of Malaysia. Most of these students are adult learners who possess a Diploma in Health Sciences and are attached to various health institutions throughout Malaysia. These students had to take a preparatory reading course during their first year to facilitate reading health-related references which are written in English. In this course, the course designers assigned two assignments which the students needed to complete through the online forum discussion. The main aim of these assignments was to assist them in developing comprehension of the two units in the course materials which were in the form of hypermedia documents. Besides the given course materials, they were also encouraged to do further reading from the prescribed websites and other relevant sources related to the themes of the two units. Due to limited contact hours face-to-face, online forum is considered an important medium of communication particularly for distance learners who have little opportunity to attend face-to-face tutorials and discussions. Hence, this study was embarked on in order to find out the benefits of the online forum as a communication platform to enhance the students' reading comprehension of health sciences materials. This study adopts the qualitative approach whereby distance learners were interviewed to collect data. They were also given a questionnaire to corroborate the data from the interviews. The online forum threaded discussions of a set of class of 22 students were also analyzed. The results of this study prove that online forums do enhance the students' reading comprehension.
\end{abstract}

Keywords: asynchronous forum, teaching and learning, reading, distance learners

\section{Introduction}

It is necessary for the researcher to provide a brief background on the role of the English language in Malaysia's education system so that the importance of a preparatory reading course at the tertiary level particularly at the National University of Malaysia (UKM) can be well understood. The national language in Malaysia is the Malay language. As such, Malay serves as a medium of communication as well as instruction. The English language is only taught as a subject at both primary and secondary schools. Before the year 2000, all subjects were taught in Malay except for English. Hence in the Malaysian context, the English language is considered as a "second" language to the Malay language. This education practice resulted in most Malaysians being able to understand and read in English; however, only a small percentage of Malaysians are highly proficient in the language. When the students enrol at the tertiary level, this lack of proficiency in the English language becomes more apparent. At the tertiary level, most references are in English. Malaysian students must understand the references in order to make academic presentations, complete their assignments and answer evaluation questions. Therefore, for allied sciences students, a preparatory reading course namely English for Life Sciences (ELS) was made compulsory. The main objective of the course is to equip students with relevant reading strategies, linguistic aspects and enrich the vocabulary of all first year students of the Allied Sciences Faculty, National University of Malaysia (UKM). The knowledge is pivotal to their reading of health sciences materials.

Allied Sciences faculty has two cohorts of students: on-campus and off-campus students. The ELS on-campus students were fully guided by the lecturers throughout the semester whereby the off-campus students or distance 
learners were instructed to become self-directed learners due to their geographical distance and also their work commitments. These distance learners who are working adultswould have to read and understand the materials on their own with minimum guidance from their lecturer and limited face-to-face assistance from their classmates. Thus, the question is: What should they do if they face reading difficulties? Zaini's study (2008) mentioned that at times, the distance learners could carry out their learning on their own, but there are times when they need to work collaboratively with other students and the lecturer or facilitator to enhance their comprehension and to reach their learning objectives. Unlike the ELS on-campus students who could discuss their reading and solve their difficulties face to face with their classmates and facilitator, the ELS distance learners could only resort to phone calls, text messages, emails, and online forum as modes of communication. In order to facilitate and enhance students' comprehension on the reading materials, we adopted the online forum as the main mode of communication between the classmates and the facilitator to facilitate each other's understandings. Therefore, it is crucial to question ourselves (who are also the course designers and facilitators)-What are the distance learners' perceptions towards online forum inenhancing their reading comprehension?

\section{Literature Review}

\subsection{Constructivist Theory}

The employment of online forum discussion is based on Vygotsky's idea. Online forum discussion is heavily influenced by the constructivism theory as this theory believes in active and collaborative learning. The proponents of constructivist theory encourage students to become self-directed learners and at the same time collaborate with other learners in the process of knowledge expansion to build their comprehension and knowledge (Bruner, 1966). Constructivist theory could be subdivided into two namely cognitive constructivist and socio constructivist.

Cognitive constructivists promote students to work on an individual basis in their process of knowledge expansion. That is, students are the ones who initiate and become mentally active in their own reading (Yahya, 2008). During the reading activity, they explore new information, navigate reading, derive meaning and extend their own understanding. The information or knowledge that appears in the reading material is not absorbed passively but developed actively by the learners. Through active and discovery activities using the three processes (explore, derive meaning \& extend their own understanding), they are able to relate their existing knowledge with the knowledge conveyed in the reading material and later develop in-depth knowledge of the learned area.

On the other hand, socio constructivists believe that the result of collaborative learning promotes better comprehension or task completion in comparison to working alone. Vygotsky (1978), a key proponent of socio-constructivist in Mitchell and Myles (1998) perceived that skilled individuals who are normally adult learners are capable of autonomous functioning or self-regulation in comparison to children or young adults. However, if the adult learners are not ready to become self-regulated or self-directed students, they need to be trained with the necessary skills as a process to become self-directed learners (Knowles \& Holton, 1998). The guidance could also be obtained through the guidance of their facilitator and assistance from their capable peers. The guidance is in the form of resources, challenging activities and mentoring. The assistance of their peers through collaborative learning could result in the students attaining or acquiring new skills and reading strategies Gradually, the percentage of assistance and guidance could be reduced according their level of readiness in becoming self-directed learners.

\subsection{Adult Learners}

It is safe to categorize the ELS distance learners as adult learners based on the definition of Knowles and Holton (1998) and Timarong (2000). According to Knowles and Holton (1998), an adult learner is: "One who has arrived at a self-concept of being responsible for one's own life. When we arrived at that point, we develop a deep psychological need to be perceived by others, and treated by others as capable of taking responsibility for ourselves. And when we find ourselves in situations where we feel that others are imposing their wills on us without our participating in making decisions affecting us, we experience a feeling often subconsciously of resentment and resistance." Another definition of adult is given by Timarong et al. (2000). These scholars define adults as individuals who are over the age of 24 and have been out of school for a period of time. Based on the given definitions, we believe that our students are under the category of adult learners which are capable of becoming self-directed learners because they can be responsible for their own learning process and can manage their time better than the young learners. As distance learners and self-directed learners, they have more freedom in making decisions about their learning styles, managing their time in completing their assignments and in 
navigating their readings. This notion also stems from the opinion of a few scholars. Adults are capable of conceptualizing the content of what they have learnt. They have a better ability to construct meaning from a text as they engage their prior knowledge or non-visual information to bring meaning to the text and this has a positive effect on their reading comprehension level (Knowles \& Holton, 1998; Miller \& Stine-Morrow, 1998; Rogers, 2002). Furthermore, adult learners are capable of appraising, managing and regulating their own reading performance (Carnine et al., 1997).

Based on these definitions and beliefs, it was deemed appropriate to introduce and later instruct the ELS distance learners to use online forum as a tool to enhance their reading comprehension since they could navigate and regulate their own reading process. They could also employ their previous knowledge and relate it with the given topics and reading materials. In this regard, the previous knowledge refers to the knowledge they obtain during the Diploma years in the same field and also their working experience on the same discipline. Nevertheless, they still need some guidance, confirmation and assistance by their peers and facilitator to optimize their reading comprehension and to prepare them for on-going assessments and final exam. These could also be obtained through their participation in the online forum discussion.

\subsection{Scaffolding in Online Forum}

Commonly referred to as "computer conferences, web forums, message boards, discussion board, discussion forums and bulletin boards" (Mason \& Rennie, 2008), the online forum in the ELS course functions as a medium to replace the physical absence of the facilitator and the classmates. Many researchers agree that the online forum is extensively used nowadays as a mode of interacting and getting feedback among students who are not comfortable to interact in class because they are shy learners (Fariza et al., 2010). Adult learners possess high affective level in comparison to young learners. They are more afraid of making mistakes and less open to be ridiculed by other people. Hence, online forum is suitable for adult learners due the geographical distance and it also allows the students to revise their sentences and ideas multiple times before they post it onto the plenary.

The benefits of adopting online forum are proven in Nor Fariza et al.'s (2010) study. The benefits highlighted in their study are: there were instances of agreement, disagreement, explanation and negotiation of meaning, help giving, sharing of knowledge and illustration of understanding as a result of participation in online discussion. This implies that the students were engaged in some fairly deep and thorough review of the topics when they discuss their comprehension in online forum (Fariza et al., 2010).According to Anderson (1991), social presence which is visible in the online forum discussion is important to ensure a collaborative learning community. In order to create ideal and collaborative online learning, the students need to become social network builders (Amelia \& Rashid, 2010). When the learners are socially connected in a relaxing online learning environment, the students feel less threatened in expressing their ideas, telling their stories and displaying their difficulties and uncertainties.

Through the collaborative learning process which is visible in group discussions, the students would normally start to be curious and later acquire the motivation, skills, and positive attitudes with the assistance of their group members (Jordan et al., 2008). When they work in a group to reach a shared goal, for instance, to reach solutions, they would receive, discuss and debate the varied suggestions given by the group members. This process of learning which prompts the students to take successive steps in solving a problem and to construct new knowledge is known as scaffolding (Jordan et al., 2008). Initially, the students were asked to discuss in depth on the definitions of certain terminologies to expose the students with the subject matter. While discussing the definitions, the students need to read from various sources which also include their academic textbooks, online sources and lecture notes. They work together by correcting each other's wrong perceptions and complement each other's knowledge (Jordan et al., 2008). These activities are also known as Team-teach. Since students may come from different learning and cultural background, this Team-teach approach is practical to cater to students' individual situations and learning pace (Jordan, 1997).To illustrate, some adult learners may only be free at odd hours due to work and family commitments. They could read and respond to the postings in the online forum according to their free time. Some students would only start posting when they believed they had reached a certain level of confidence in understanding about the discussed topic. Online forum discussion makes reading activities more interesting as the students are directly involved in their reading process. Kumbruck (1998) supports that direct involvement in reading process could yield better reading comprehension.

\section{Research Design}

\subsection{Setting}

It is also important for us to provide more information on the ELS course for distance learners. In 2008 and 2009, there were two cohorts of students at the Faculty of Allied Sciences, namely distance learners and on-campus 
students. As course designers, we needed to design the ELS course module and teach both the on-campus and distance learners, using the module that we had designed. The main objectives of the ELS course is to equip students with relevant reading strategies, linguistic aspects and enrich the vocabulary of all first year students of the Allied Sciences Faculty, National University of Malaysia (UKM) in order to enable them to read and comprehend health sciences materials.

Most of the distance learners studied on a part time basis due to family and work commitments. Their age range was between 30 and 45 years old. These students had already obtained a Diploma in Health Sciences, and were currently working at hospitals, municipal councils and universities all over Malaysia. Therefore, as adult and distance learners, these students of the Allied Sciences Faculty, UKM, were only required to attend twelve hours of face-to-face tutorials in the initial two weeks namely Week 1 and 2.

There are 16 weeks in each semester. At the end of Week 2, they returned to their respective hometowns throughout Malaysia and were expected to become independent or self-directed learners for the following 12 weeks. The only opportunity for the instructors to meet up with the students again was during the final exam which was scheduled in Week 15 or 16. From Week 3 to Week 14, they were supposed to read, listen, and watch the hypermedia documents which had been prepared as their learning material.

The ELS materials were in the form of hypermedia documents. The hypermedia documents were uploaded onto the UKM website before the class started and during the course period. In this context, hypermedia documents refer to hypertexts that provide links, not only from text to text but from texts to various media such as sound, images, animation and/or video (Beatty, 2003). The hypermedia documents were divided into six units according to themes under the domain of health sciences. The hypermedia documents consisted of reading materials from various sources, reading activities, linguistic input, video clips, PowerPoint slides, suggested websites and film.

Based on their understanding of the hypermedia documents, they were instructed to make academic presentations, complete the given two online forum assignments and answer evaluation questions namely online quizzes and online discussions. The academic presentations were conducted in the first two weeks of class. They presented via face-to-face after the students attended the face-to-face tutorials. The students were given a few articles related to the presentations in Week 1 and they discussed those articles in class. Based on their understanding of those articles and other researched articles on the same title, they prepared and presented their understanding of the articles with their partners. They were also given another topic to be discussed in small groups of four. The small group discussion was evaluated. These face-to-face small group discussion and presentation familiarise the students with each other and develop positive rapport with each other. It is also essential for the students to develop a strong bond among themselves to reduce their affective filter level when participating in online forum. This notion is further supported by Dudley-Evans and St John (1998) in Takad and Md Zulfeqar (2012), the collaboration among the students and the facilitator was extended when they work together outside class. In the process of completing the two online forum assignments, the students had to read and listen to the hypermedia documents and other relevant sources. In each online forum assignment, the students were expected to post at least five postings into the asynchronous forum. They had to post their postings between Week 5 to Week 14.One of the online forum assignments is indicated in Figure 1.

ONLINE FORUM $(10 \%)$
Use the suggested websites to substantiate your opinions.
http://www.schizophrenia.com/family/sz.overview.htm
$\underline{\mathrm{http}: / / \text { www. nobelprize.org/nobel prizes/economics/ }}$
$\underline{\mathrm{http}: / / \text { www.mentalhealth.org.uk/feedingminds/ }}$
$\underline{\mathrm{http}: / / \text { www.emedicinehealth.com/schizophrenia/article em.htm }}$
$\underline{\mathrm{http}: / / \text { www.schizophrenia.com/ }}$
$\underline{\mathrm{http}: / / \text { www.mentalhealth.com/story/p52.html }}$
Read the article "Moving Lives Forward" and discuss in your
ONLINE FORUM:
a) The problems of treating Schizophrenia in Malaysia.
b) Suggest ways to promote greater awareness of Schizophrenia among
Malaysians.

Figure 1. Online forum assignment 1 
As the course designers and facilitators who have been teaching this group of distance learners, we know that most of these distance learners are not highly proficient in English. We discovered that these adult learners were more afraid to make mistakes in comparison to on-campus students. Therefore, in order to promote their participation in the online forum, their grammatical and spelling errors were not highlighted nor corrected by the facilitators. We also did not penalize the students if they gave false information due to their misunderstanding or misinterpretation of the subject matter. If the facilitator corrected these errors or misinterpretations, the students would feel inhibited from participating because these adult learners feel embarrassed to express themselves when their language deficiency and limited knowledge on the subject matter are highlighted. Thus, we just let the students perform peer correction which simulates real face-to-face discussion in a real problem-solving context. In the process of peer correction, they would engage in deep thinking and argue before they could reach a certain level of consensus (David et al., 1999). Our intention was only to provide a safe and controllable setting for the students to collaborate with each other in building each other's knowledge. Supyan and Zuraidah (2008) believe that the focus of the online forum is to promote active participation among the students, and therefore, language accuracy should not be overemphasized. The online discussion was supposed to help them to express their beliefs, perspectives, arguments and to enable them to relate to the stories of others. Our prime aim was to encourage the students to do extensive and intensive reading on the issues discussed. That is, the questions posted were to encourage the students to read the prepared hypermedia documents and other related sources to enhance their comprehension of the units. In sum, the discussions were aimed at enabling the students to have fuller comprehension of the two units in the hypermedia documents. The mark of each assignment was 10 percent of the total marks. It was essential for the course designers to allocate marks in order to ensure the students' participation and to give positive reward.

During independent reading, these students only used hyperlinks to the words that they were not familiar with. They also manipulated other sources to illuminate their uncertainties. However, are these steps sufficient to enable them to have full comprehension of the reading materials? The earlier findings of Maslawati et al.'s (2010) study prove that one of the reasons that most ELS distance learners could not have full comprehension of the given hypermedia documents is due to the fact that individual semantic structures of information differ from each other and the hypertext's author. Asynchronous forum was employed because the students could send delayed responses since most of them work at odd hours. Delayed responses also provided ample time for the students to do reflection, thus more reflective contributions could be produced (Bender, 2003). During reflection, the students utilized higher order thinking skills such as analyzing, synthesizing, and reconstructing meanings. Simultaneously, they made more associations with their long term memory which resulted in higher-level learning (Amin, 2008). The students' discussions via asynchronous forum were reflected in their completion of two assignments. In the process of completing both assignments, the students had to read and listen to the hypermedia documents and other relevant sources. In each assignment, the students were expected to post at least five postings into the asynchronous forum. They had to post their postings between Week 5 to Week 14 .

\subsection{Methodology and Procedure}

This study employed qualitative methods of data collection. A case study design was utilized as this study comprised one of the groups of ELS distance learners. In this study, a group of 22 students was treated as a single entity which represented the target population (Hittleman \& Simon, 2006). According to Merriam (2009), a case study should be employed when the aim of a study is to gain a comprehensive understanding of a situation and a process rather than the outcome or product of the phenomena. She adds that a combination of research instruments should be used to cross illuminate the data evidence or to serve the purpose of triangulation. We engaged three research tools, namely semi-structured interview questions, a set questionnaire and document analysis (the online forum discussion threads). The names in the online forum discussion threads are pseudonyms to protect the identities of the participants.

In order to elicit more in-depth views, we sought for volunteers from the same group to be interviewed. Yin (2009) points out that the interview is an essential source of data in a case study because it concerns behavioural events. Eight students from the group of 22 had volunteered. However, only seven volunteers were able to give full commitment until the end of this study. They were labelled as INTAM, INTRA, INFA, INTFARH, INTLI, INTAD, and INTA. All the names that appear in this article are pseudonyms to protect their identities. Pseudonyms are also important to enable the respondents to respond honestly and accurately (Creswell, 2009). They were interviewed and given a set questionnaire after the completion of each assignment or after the due date of each assignment. The questionnaire was given before the interview session. The questionnaire was on the students' perception on how online forum could enhance their reading comprehension of the units. The data was interpreted using the mean scores. The Likert scale ranged from 1 to 4: 1-strongly disagree, 2- disagree, 3- agree, 


\section{4-strongly agree.}

Transcribing was the first phase of data analysis. Transcription is a process of transferring the data on the audio tapes into textual forms (Dornyei, 2007; Creswell, 2009). Before the data was analyzed, the researcher listened to the audio-tape and transcribed the verbal report verbatim. Even the non-verbal expressions like pauses, grumbles, hesitations, uncertainties puzzles and others were transcribed. Undoubtedly, some body language or non-verbal expressions namely intonation, stress, paralinguistic factors (acoustic sounds) or non-vocal sounds were missing (Dornyei, 2007). We did not make any changes in the online thread of discussions. The data from the interviews and online forum discussion threads was coded to note emerging themes, which assisted the analysis. The analysis was then compared to the content of the two units and literature review. Data gathered from the interviews, the online forum thread of discussions and the questionnaire was then collated to provide an overview on the benefits of asynchronous forum in enhancing students' comprehension.

\section{Findings and Discussion}

1) Based on the findings, we were able to derive six benefits of the asynchronous forum. The asynchronous forum has successfully become a platform for the students to:

2) Expand each other's ideas and confirm each other's understanding

3) Provide motivation, express their agreements, criticisms, seek comments, confirmation and feedback

4) Work collaboratively to solve each other's problems and difficulties

5) Have ample time to read extensively

6) Have adequate time to compose

7) Gain a lot of information from a myriad of sources

In this paper, we will discuss only two out of the six benefits. The episodes which appear in the following discussion entail two sources which are the online forum threaded discussions and the semi-structured interview responses.

\subsection{Expand Each Other's Ideas and Confirm Each Other's Understanding}

One of the contributions of the asynchronous forum is that it enables the students to expand their ideas and confirm each other's understanding. From the threaded discussion, we could identify that most respondents preferred to expand other students' postings. At the initial stage, in Unit 1 they provided definitions of 'Schizophrenia'. In the second assignment in Unit 2 which was on 'Designer Babies', the students also included the various definitions of both themes ('Designer Babies' \& 'Schizophrenia') at the initial stage. While discussing the definitions, they complemented each other's definitions using the definitions taken from multiple sources. If a definition originated from a website, they would include the website's address in the form of a hyperlink to encourage other readers to surf the website. After many postings on the definitions, most of the students had a comprehensive idea on the definition as can be traced in the following discussion thread. This is parallel to Kumbruck's (1997) and Jordan's (1997) viewpoint. Kumbruck stated that online forum discussion makes reading activities more interesting as the students are directly involved in their reading process which could yield better reading comprehension. Jordan mentioned that while discussing the definitions, the students need to read from various sources which also include their academic textbooks, online sources and lecture notes. They work together by correcting each other's wrong perceptions and complement each other's knowledge. Talestra et al. (2004) also concur with the viewpoints of Kumbruck and Jordan. According to them, these reading activities are especially useful to novice readers. Novice readers will definitely need more information from other sources to enable them to relate to their existing ideas and knowledge. The feedbacks from the interviews with the researchers indicate that the students' knowledge was from their diploma education and workplace experience. They also admitted that the discussions with the doctors and other medical practitioners at their workplace also confirm their understanding on the issue discussed and their postings are the evidence of such effort. The students' enthusiasm of accumulating new information, expanding each other's ideas and confirming each other's understanding forged them to go ahead with their reading (Ramesh \& Sanjaya, 2007)

FROM: INTAM (01/14/09 9:54 PM $\quad$ GMT $\quad$-06:00) !! HYPERLINK "http://www.nicenet.org/ICA/class/message_send.cfm?user_id=2033395\&conf_topic_id=626919\&subject=" ๆ Send a personal message to INTAM $^{\perp}$ ]

a lot of friends discussing about the definition, sign and symptom and everything... everyone should be clear in this right now... I think we should discuss more in pathology or the changes in brain also the stigma or the perception of people towards patient suffered from Schizophrenia. 
The next move was to navigate the other students to another phase of discussion. The second phase was expanding the ideas of others by taking a stance on the issue. Normally, the students could only take a stance when they had already accumulated some knowledge regarding the matter through intensive and extensive reading on the two units. Some jargon terms such as 'genome' and 'gene' were elaborated and confirmed. Through the discussion or debate, they realized the loopholes of the debated entry and thus tried to patch up the loopholes, particularly in the areas where they were unsure or had limited knowledge.

“... sometimes we discuss a topic until we have much understanding on the issue. May be someone does not know about genetic so online forum is important as other people who are knowledgeable about genetic will explain about genome."

The respondents realized the loopholes in their explanations and tried to explain the matter further with the intention of making others grasp the points of their explanations or the stance they took, as can be seen in one of the student's entry:

“... even though 5 entries is enough but if I'm not mistaken one of them disagree. I reply by giving further explanations".

They also corrected their classmates' viewpoints. Consequently, a more in-depth and fruitful discussion was exhibited, thereby heightening the students' understanding of the units. When the respondents were posted with the statement in the given questionnaire: "I find that the discussion in the online forum assists me in my reading comprehension", the mean for this statement was 3.25 (refer to the abovementioned Likert Scale), which implies that the students were in agreement with the statement. This statement was echoed by two respondents, namely INTFA and INTLI, during the interview sessions when they respectively uttered:

"one of the means for us to develop our ideas are to discuss all the answers, pour all ideas there" and "... the online forum really helps me to keep track of the discussion threads and it makes me know what's happening under this title".

\subsection{Be Able to Provide Motivation, Express Their Agreements, Disagreements, Criticisms, Seek} Comments/Opinions, Confirmation and Feedback

The data from the questionnaire reveals that all the respondents agreed that the asynchronous forum has created compelling opportunities for them to interact with other group members, thus creating social interaction among the students. Social interactions which are listed as follow and discussed in this subsection were important as they made it more motivating for the students to participate in the online forum discussions and to work collaboratively in order to reach fuller comprehension:

1) Providing motivation for the students to participate and share their reading, viewpoints and stories

2) Seeking comments/opinions

3) Seeking confirmation and feedback from their classmates

The online forum acts as a fundamental communication tool in this academic environment. It allows interaction between different agents of the learning-teaching process. The interaction is necessary for work groups, exchanging experiences, providing help by a tutor, resolving doubts and others (Bri et al., 2009).

\subsubsection{Providing Motivation for the Students to Participate and Share Their Reading, Viewpoints and Stories}

The respondents felt that what they wrote was for others to comprehend and gain knowledge, and as such the information was not lost in cyber space. Thus, they provided feedback to each other to serve the purpose of interaction, and not merely to obtain marks. This remark was uttered by three respondents, namely INTRA, INTAM and INTFA. INTRA said,

"I hope that they will read and may be they could comment my entry lah. Even though my entry does not discuss much but at least it could open up their mind which enables them to provide feedback".

INTFA also gave similar feedback,

"If we just send our entry, we do not know who will respond to us or the respond is very slow. So not very interestinglah."

INTAM added,

"... because for me the most important thing is for us to exchange our opinion lah"

It can be concluded that they were motivated to participate in the online forum when they felt a warm atmosphere in the group discussion. This conclusion is further confirmed when the respondents were posted with 
the statement in the given questionnaire: "My discussion in the online forum helps me increase my motivation in learning"; the mean for this statement is 3.0 implying that the students are in agreement with the statement.

At first, these students felt shy to send in their entries and the only pushing factor was the allocated marks. Gradually, they were able to reduce their level of apprehension, and started to feel comfortable with each other as expressed by two of the respondents, namely INTLI:

"Very shy. Shy but I still must send my entries. At first my sentences are horrible but after that no so bad lah because I don't see other people's face. There are so many entries here, they don't care who's the sender kan, so not embarrassing to send any entries any more."

And INTFA:

"Actually I feel forced to send my entry because of the marks even though I'm not good in my grammar but after some time I don't mind."

\subsubsection{Seeking Comments/Opinions}

The following episodes from the threaded online forum discussion illustrate that the respondents acknowledged other people's comments and sought opinions from others.

FROM: INTLI(01/18/09 8:47 PM GMT -06:00) [Send a personal message to INTLI]

... I hope that all of you can comment about my point of views and have further discussion about the problems that are occur in treating patients with schizophrenia to the basic root.

FROM: ma (03/07/09 12:57 AM GMT -06:00) [Send a personal message to ma]

But is this right? In these cases, parents and doctors are creating a child to act as an organ-donating factory. How will the child feel? The child may feel that they were only born to be a help to their older brother or sister. Children should be loved and cherished for themselves and not what they can do for others. Alterations made by genetic engineering would be passed on from one generation to the next. My question is what rights have parents to choose what genetic characteristics are best for their children, and their children's children? Will the children react against the genetic changes that their parents have chosen for them?

Who is responsible for genetic modification of a child? The parents? The doctors? Or the Government?

FROM: INTAM(03/17/09 9:54 PM GMT -06:00)

In your opinion, what would happen to future mankind if we were allowed to choose specific features/characteristics of our children?

These activities prove that they possessed a high level of curiosity on the topic discussed which prompted them to become active contributors. When they sought other people's comments, it also means that they were willing to admit their own knowledge gaps and display their desire to overcome those gaps. According to Barnes (2003) only if students are in the comfort zone of the collaborative learning community, would they admit their knowledge gaps and depend on their group members as well as their instructor to fill the gaps. Nuttal (2005) also contends that motivation and attitude are interrelated in the reading process. Hence, it is essential that a comfortable atmosphere exists to promote extensive and intensive reading of the two units.

\subsubsection{Seeking Confirmation and Feedback from Their Classmates}

When these students sought feedback from others (refer to the following episodes), it means that they sought confirmation, they wanted to be commented on, and they displayed a high level of curiosity.

FROM: XXY (02/16/09 9:12 AM GMT -06:00) [Send a personal message toXXY]

\section{SUBJECT: RE: designer babies}

I agree with what you have mentioned $\mathrm{ZZ}$. In Islam, there are certain things that we can practise during pregnancy in order to choose gender, physical and intellectual of the baby. For example, to have male baby it is advice to the parents to reads Al-Quran surah Yusuf and if you want to have female you can reads surah Maryam. It is also advisable for the pregnant lady to take honey and dates in order to have genius baby. Am I right?... correct me if I'm wrong... thanks.

Their high level of curiosity resulted in their taking the move to read and comprehend the postings. In addition, the students felt encouraged and looked forward to receiving comments as well as to reading the postings of others. Some of these students did not feel confident with the content of their postings and prodded other members to confirm the validity of their contents. The responses posted by others made them realize their errors and they thus made attempts to correct their errors. This notion is clearly expressed by INTAD who mentioned, 
“OK, a... the online forum really helps me. First, sometimes we think that we're right but when others go against our opinion then only we realize our mistakes."

\section{Conclusion}

At the National University of Malaysia, most distance learners are adult learners who register for an online course because they have to combine jobs with part-time study and family life. This scenario explains the reason why distance education has become a dominant mode of higher education among adult learners (Inoue, 2007). Overall, the findings of this small-scale study suggest that asynchronous forum brings a lot of benefits to distance learners, particularly second language adult learners in enhancing their reading comprehension. It is safe to conclude that asynchronous forum is able to develop social interactions that provide the guidance and support essential for distance learners to succeed in their studies, especially with regard to heightening the students' reading comprehension level. The students could use asynchronous forum as a platform to expand and confirm each other's ideas. They could seek comments, opinions, confirmation and feedback from others which complemented their existing understanding and knowledge. These activities resulted in their feeling curious and enthusiastic, thereby motivating them to read intensively and extensively on the two themes which stem from the two units. The intensive and extensive reading allowed them to gain better reading comprehension. In the process of responding to others, the students carried out reflection; thus more reflective contributions were produced. Prior to posting any ideas, the respondents were involved in a reflective process whereby they tried to comprehend, examine and reflect on what they had read from the reading materials as well as the online responses. Ultimately, the social interaction created a sense of belonging which is very important for distance learners.

\section{References}

Amelia, A., \& Rashid, M. A. (2010). Investigating the Roles of students in the development of a collaborative learning community through networked learning: a Malaysia perspective. Proceedings of the 5th International Conference On eLearning, 157-162. Penang: Universiti Sains Malaysia.

Anderson, N. J. (1991). Individual differences in strategy use in second language reading and testing. The Modern Language Journal, 75(4), 460-472. http://dx.doi.org/10.1111/j.1540-4781.1991.tb05384.x

Barnes, S. B. (2003). Computer-mediated communication: Human-to-Human communication across the Internet. Pearson Education: Boston.

Beatty, K. (2003). In N. C. Christopher, \& R. H. David (Eds.), Teaching and researching computer-assisted language learning. London: Pearson Education.

Bender, T. (2003). Discussion-based online teaching to enhance student learning. Sterling: Stylus.

Bri, D., Garcia, M., Coll, H., \& Lloret, M. (2009). A Study of Virtual Learning Environments WSEAS Transactions on Advances in Engineering Education, 1(6), 33-43.

Bruner, J. S. (1966). Toward a theory of instruction. Cambridge: Belkapp Press.

Carnine, D. W., Silbert, J., \& Kameenui, E. J. (1997). Direct instruction reading (3rd ed.). London: Prentice Halls.

Creswell, J. W. (2009). Research design: Qualitative, quantitative and mixed methods approaches (3rd ed.). Thousand Oaks CA, : SAGE Publications.

David, H. J., Kyle, L. P., \& Brent, G. W. (1999). Learning with technology: a constructivist perspective. New Jersey: Prentice Hall.

Dornyei, Z. (2007). Research methods in applied linguistics: Quantitative, qualitative and mixed methodologies. Oxford: Oxford University Press.

Hittleman, D. R., \& Simon, A. J. (2006). Interpreting educational research (4th ed.). New Jersey: Merrill Prentice Hall.

Inoue, Y. (2007). Online education for lifelong learning. London: Information Science Publishing. http://dx.doi.org/10.4018/978-1-59904-319-7

Jordan, A., Carlile, O., \& Stack, A. (2008). Approaches to learning: A guide for teachers. New York: McGraw Hill.

Jordan, R. R. (1997). English for Academic Purposes: A guide and resource book for teachers. Cambridge: Cambridge University Press. http://dx.doi.org/10.1017/CBO9780511733062 
Knowles, M. S., \& Holton III, E. F. (1998). The adult learners. Houston: Gulf Publishing Company.

Kumbruck, C. (1998). Hypertext reading: Nnovice vs. expert reading. Journal of Research in Reading, 21(2), 160-172. http://dx.doi.org/10.1111/1467-9817.00051

Maslawati, M., Supyan, H., \& Zaini, A. (2010). Developing a blended course: Difficulties faced by the adult learners in reading hypertexts. Proceedings of the 5th International Conference On eLearning, 157-162. Penang: Universiti Sains Malaysia.

Mason, R., \& Rennie, F. (2008). E-learning and social networking handbook: Rresources for higher education. New York: Routledge \& Francis.

Merriam, S. B. (2009). Qualitative research: a guide to design and implementation. San Francisco: Jossey-Bass.

Miller, L. M. S., \& Stine-Morrow, E. A. L. (1998). Aging and the effects of knowledge on online reading strategies. Journal of Gerontology: Psychological Sciences, 53B, 222-233. http://dx.doi.org/10.1093/geronb/53B.4.P223

Mitchell, R., \& Myles, F. (1998). Second language theories. London: Arnold Publishers.

Mohamed, A. (2008). Foundations of educational theory for online learning. In T. Anderson (Ed.), The Theory and Practice of Online Learning (2nd ed.), 15-45. Retrieved August 10, 2011, from http://www.aupress.ca/books/120146/ebook/99Z_Anderson_2008-Theory_and_Practice_of_Online_Learni ng.pdf

Mohd et al. (2010). E-learning: Analysis of online discussion forums in promoting knowledge construction through collaborative learning WSEAS Transactions on Communications, 9(1), 53-62.

Nuttall, C. (2005). Teaching reading skills in a foreign language (2nd ed.). Oxford: Heinemann.

Ramesh, C. S., \& Sanjaya, M. (2007). Global elearning practices: An introduction. In C. S. Ramesh \& Sanjaya (Eds.), Cases on global elearning practices: Successes and Pitfalls (pp. 1-12). United Kingdom: Ideagroup Inc.

Rogers, A. (2002). Teaching Adults. London: Oxford University Press.

Supyan, H., \& Zuraidah, A. K. (2008). Creating a bigger Z. P. D. for ESL Learners via Online Forum. Paperpresented at Teaching \& Learning Conference, Orlando, Florida 2-5 Jan 2008. Organized by The Clute Institute, USA.

Timarong, A., Temanguil, M., \& Sukrad, W. (2000). Adult learning and learners. Pacific Resources for Education and Learning. Retrieved August 10, 2011, from http://www.prel.org/products/pr_adult learners.htm

Vygotsky, L. S. (1978). Mind and society. Cambridge: Harvard University Press.

Othman, Y. (2008). Proses \& strategi: Membaca berkesan. Serdang: Penerbit Universiti Putra Malaysia.

Yin, R. K. (2009). Case study research: Design and methods (4th ed.). Los Angeles: SAGE Publications.

Zaini, A. (2008). Language learning strategies in an online English writing course: Aa case study. Ph.D. Thesis. Universiti Kebangsaan Malaysia.

\section{Copyrights}

Copyright for this article is retained by the author(s), with first publication rights granted to the journal.

This is an open-access article distributed under the terms and conditions of the Creative Commons Attribution license (http://creativecommons.org/licenses/by/3.0/). 